\title{
Environmental transmission electron microscopy investigations of Pt-Fe2O3 nanoparticles for nucleating carbon nanotubes
}

He, Maoshuai; Jin, Hua; Zhang, Lili; Jiang, Hua; Yang, Tao; Cui, Hongzhi; Fossard, Frédéric; Wagner, Jakob Birkedal; Karppinen, Maarit; Kauppinen, Esko I.

Total number of authors:

11

Published in:

Carbon

Link to article, DOI:

10.1016/j.carbon.2016.09.026

Publication date:

2016

Document Version

Peer reviewed version

Link back to DTU Orbit

Citation (APA):

He, M., Jin, H., Zhang, L., Jiang, H., Yang, T., Cui, H., Fossard, F., Wagner, J. B., Karppinen, M., Kauppinen, E. I., \& Loiseau, A. (2016). Environmental transmission electron microscopy investigations of $\mathrm{Pt}-\mathrm{Fe}_{2} \mathrm{O}_{3}$ nanoparticles for nucleating carbon nanotubes. Carbon, 110, 243-248.

https://doi.org/10.1016/j.carbon.2016.09.026

\section{General rights}

Copyright and moral rights for the publications made accessible in the public portal are retained by the authors and/or other copyright owners and it is a condition of accessing publications that users recognise and abide by the legal requirements associated with these rights.

- Users may download and print one copy of any publication from the public portal for the purpose of private study or research.

- You may not further distribute the material or use it for any profit-making activity or commercial gain

- You may freely distribute the URL identifying the publication in the public portal 


\section{Environmental Transmission Electron Microscopy Investigations of $\mathrm{Pt}-\mathrm{Fe}_{2} \mathrm{O}_{3}$ Nanoparticles for Nucleating Carbon Nanotubes}

Maoshuai He ${ }^{1,2^{*}}$, Hua $\mathrm{Jin}^{3}$, Lili Zhang ${ }^{4}$, Hua Jiang ${ }^{5}$, Tao Yang ${ }^{6}$, Hongzhi Cui ${ }^{1 *}$, Frédéric Fossard ${ }^{2}$, Jakob B. Wagner ${ }^{4}$, Maarit Karppinen ${ }^{3}$, Esko I. Kauppinen ${ }^{5}$, Annick Loiseau ${ }^{2}$

1. School of Materials Science and Engineering, Shandong University of Science and Technology, 266590 Qingdao, People's Republic of China

2. Laboratoire d'Étude des Microstructures, ONERA-CNRS, BP 72, 92322 Châtillon CEDEX, France

3. Department of Chemistry, Aalto University School of Chemical Technology, P.O. Box 16100, FI00076 Aalto, Finland

4. Center for Electron Nanoscopy, Technical University of Denmark, DK-2800 Kongens Lyngby, Denmark

5. Department of Applied Physics, Aalto University School of Science, P.O. Box 15100, FI-00076 Aalto, Finland

6. School of Chemical Engineering, Huaihai Institute of Technology, 222005 Lianyungang, People's Republic of China

\section{Corresponding Author}

* Correspondence should be addressed to: Maoshuai He, email: maoshuai.he@sdust.edu.cn,Tel:+86 53286057925; Hongzhi Cui, email: cuihongzhi1965@163.com, Tel:+86 53280681145 


\section{Abstract:}

Elucidating the evolution of bimetallic catalyst for nucleating carbon nanotube has been challenging. In this work, acorn-like $\mathrm{Pt}-\mathrm{Fe}_{2} \mathrm{O}_{3}$ nanoparticles are developed for the growth of single-walled carbon nanotubes (SWCNTs) by chemical vapor deposition. Using in situ environmental transmission electron microscopy, restructuring of the acorn-like $\mathrm{Pt}_{-} \mathrm{Fe}_{2} \mathrm{O}_{3}$ nanoparticles at reaction conditions is investigated. Upon heating to reaction temperature, $\varepsilon-\mathrm{Fe}_{2} \mathrm{O}_{3}$ is converted to $\beta-\mathrm{Fe}_{2} \mathrm{O}_{3}$, which can be subsequently reduced to metallic Fe once introducing $\mathrm{CO}$. As Pt promotes the carburization of Fe, part of the metallic Fe reacts with active carbon atoms to form $\mathrm{Fe}_{2.5} \mathrm{C}$ instead of $\mathrm{Fe}_{3} \mathrm{C}$, catalyzing the nucleation of carbon nanotubes. Nanobeam electron diffraction characterizations on SWCNTs grown under ambient pressure at $800{ }^{\circ} \mathrm{C}$ demonstrate that their chiral angle and diameter distributions are similar to those of SWCNTs grown on monometallic Fe. The results further indicate that the active components in both the catalysts, determining the chirality distribution of SWCNTs, are similar. In addition, Pt facilitates the reduction of $\mathrm{Fe}_{2} \mathrm{O}_{3}$, rendering SWCNT growth at a relatively low temperature of $700{ }^{\circ} \mathrm{C}$. This work provides a profound understanding of the structural reconstruction in bimetallic catalyst, shedding more light on designing novel catalysts for the growth of SWCNTs.

Keywords: single-walled carbon nanotube, Pt-Fe bimetallic catalyst, chirality, structural evolution, in situ environmental transmission electron microscopy

\section{Introduction}

Since the landmark work on the synthesis of single-walled carbon nanotubes (SWCNTs) by electric arc technique using Fe-containing cathode,[1] the search for better catalysts has been one of the main tasks in controlled synthesis of SWCNTs. Of numerous catalysts studied, bimetallic catalysts have attracted particular interests due to their high activity and better control over SWCNT structures by 
chemical vapor deposition (CVD) technique. As the result of adding a second metal, catalysts, such as CoMo,[2] CuFe,[3] RuFe,[4] PtCo[5] and WCo,[6, 7] lead to higher carbon nanotube yields and narrower chirality distributions compared to their monometallic counterparts. In spite of these progresses, secret behinds the successful growth is far from being clarified. For example, a mysterious WCo bimetallic system has been reported by two research groups to selectively grow $(12,6)$ SWCNTs. [6, 7] Yang et al.[6] proposed that the fabrication of stable $\mathrm{W}_{6} \mathrm{Co} 7$ alloy is responsible for the preferential synthesis of $(12,6)$ SWCNT. While recent work by An et al.[7] identified an intermediate structure of $\mathrm{Co}_{6} \mathrm{~W}_{6} \mathrm{C}$, where most of $\mathrm{W}$ atoms disappear after 5 min CVD growth, indicating the complexity in determining the active catalyst components for SWCNT synthesis.

Pt-based bimetallic particles have long been applied as excellent catalysts for generating carbonaceous deposits, such as carbon filaments and SWCNTs.[5, 8, 9] Pioneer work by Bark et al., [8] reported the formation of filaments when heating Pt-Fe particles in acetylene. It was discovered that, with the addition of Pt into Fe catalyst, the growth rate of filament increased two orders of magnitude.[8] Using PtCo catalyst, Liu et al.[5] achieved a narrow SWCNT chirality distribution at a relatively high temperature of $800{ }^{\circ} \mathrm{C}$. Recently, Ohashi et al.[9] prepared half-buried FePt between deposited MgO for growing vertically aligned SWCNTs with metallic chirality.

Besides the achievements in carbon nanotube synthesis using Pt-based catalyst, uncovering the structure of catalyst particles under reaction conditions is of fundamental importance in understanding SWCNT nucleation mechanisms and establishing structure correlations between catalysts and SWCNTs. Although alloy formation was observed after CVD growth by ex situ characterizations, [5, 9] some works suggest that separation of the alloy components could occur under certain conditions.[8, 10] In order to address the detailed structural change and track the evolution of catalyst nanoparticles, it is necessary to 
map the atomic structure in reactive environments using in situ environmental transmission electron microscopy (TEM).[11]

In the work reported here, we present an acorn-like $\mathrm{Pt}_{-} \mathrm{Fe}_{2} \mathrm{O}_{3}$ catalyst for the growth of carbon nanotubes. Combined with ex situ TEM characterizations on catalyst nanoparticles before and after CVD growth, in situ environmental TEM was carried out to clarify the structural dynamics of such hybrid nanoparticles in nucleating carbon nanotubes. In addition, SWCNTs grown at different temperatures will be characterized and compared with those synthesized on monometallic Fe.

\section{Materials and methods}

\subsection{Formation of acorn-like Pt-Fe $\mathrm{O}_{3}$ catalyst}

Similar to the previously reported Fe-Ti-O catalyst,[12] the $\mathrm{Pt}_{-} \mathrm{Fe}_{2} \mathrm{O}_{3}$ catalyst was prepared by combining Pt layer deposition onto premade Fe nanoparticles with subsequent high-temperature air calcination. Briefly, $\mathrm{FeO}_{\mathrm{x}}$ nanoparticles generated by hydrolysis of ferric chloride[13] were first casted onto $\mathrm{Si}_{3} \mathrm{~N}_{4}$ TEM grids, a thin layer of Pt was then sputtered onto the grids with a current of $10 \mathrm{~mA}$ for 1 min in an Emitech K100X glow discharge unit. The catalyst was finally annealed at $800{ }^{\circ} \mathrm{C}$ for $20 \mathrm{~h}$ in a muffle furnace.

\subsection{Growth of carbon nanotube with $\mathrm{Pt}-\mathrm{Fe}_{2} \mathrm{O}_{3}$ catalyst}

Carbon nanotubes were grown by CVD. Pt-Fe $\mathrm{O}_{3}$ catalyst supported by $\mathrm{Si}_{3} \mathrm{~N}_{4} \mathrm{TEM}$ grid was loaded into a horizontal CVD reactor followed by flushing with $200 \mathrm{~cm}^{3} / \mathrm{min}$ helium. After reaching the desired temperature, $\mathrm{CO}$ with a flow rate of $200 \mathrm{~cm}^{3} / \mathrm{min}$ was introduced to the CVD reactor, in place of helium stream. CO was turned off after $1 \mathrm{~h}$ and the CVD reactor was cooled under helium environment. 


\subsection{Characterizations of $\mathrm{Pt}_{-} \mathrm{Fe}_{2} \mathrm{O}_{3}$ catalyst and carbon nanotubes}

TEM observations of $\mathrm{Pt}_{-} \mathrm{Fe}_{2} \mathrm{O}_{3}$ nanoparticles were carried out on a JEOL-2200FS TEM and a Zeiss LIBRA 200FMC TEM. Elemental analysis was performed by energy dispersive X-ray (EDX) spectroscopy and electron energy-loss spectroscopy (EELS). The structure and morphology of carbon nanotubes were studied by a JEOL-2200FS TEM operated at $80 \mathrm{kV}$. Electron diffraction patterns of randomly distributed carbon nanotubes were taken to determine the chirality and diameter distributions of carbon nanotubes.

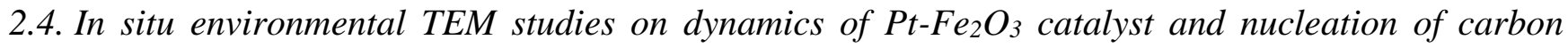
nanotube

Pt-Fe ${ }_{2} \mathrm{O}_{3}$ catalyst supported by a $\mathrm{Si}_{3} \mathrm{~N}_{4}$ TEM grid was mounted in a Gatan heating holder, which was then inserted in an FEI Titan 80-300ST environmental TEM and heated to $700{ }^{\circ} \mathrm{C}$ in vacuum. Subsequently, a flow of $\mathrm{CO}\left(6 \mathrm{~cm}^{3} / \mathrm{min}\right)$ was introduced into the TEM chamber to stabilize at a pressure of 8 mbar. The structural evolution of the catalyst particles was monitored in real time during the chemical reaction at $300 \mathrm{kV}$.

\section{Results and Discussion}

\subsection{Characterizations of $\mathrm{Pt}_{-} \mathrm{Fe}_{2} \mathrm{O}_{3}$ catalyst before and after $\mathrm{CVD}$ growth}

ESI Figure S1a presents a TEM close view image of nanoparticles prepared by Pt deposition onto iron oxide nanoparticles followed by high temperature calcination. A detailed examination shows that the acorn-like particles consist of a dark embryo partly enclosed by a light cupule. On the basis of the TEM image (Figure 1a) and its corresponding fast Fourier transform (FFT) pattern (Figure 1b), the dark embryo can be well assigned as face centered cubic (FCC) structured Pt with a lattice parameter of 0.393 
nm (pdf card: 04-0802). The lattice spacing measured from the TEM image is $0.23 \mathrm{~nm}$ (Figure 1a), resembling its (111) plane spacing $(0.227 \mathrm{~nm})$. Similarly, the cupule in light contrast is indexed as orthorhombic $\mathrm{Fe}_{2} \mathrm{O}_{3}(\mathrm{a}=0.509 \mathrm{~nm}, \mathrm{~b}=0.878 \mathrm{~nm}, \mathrm{c}=0.943 \mathrm{~nm}$, pdf card: $52-1449)$ based on the structural analysis of particle shown in Figure 1c and its FFT pattern (Figure 1d).

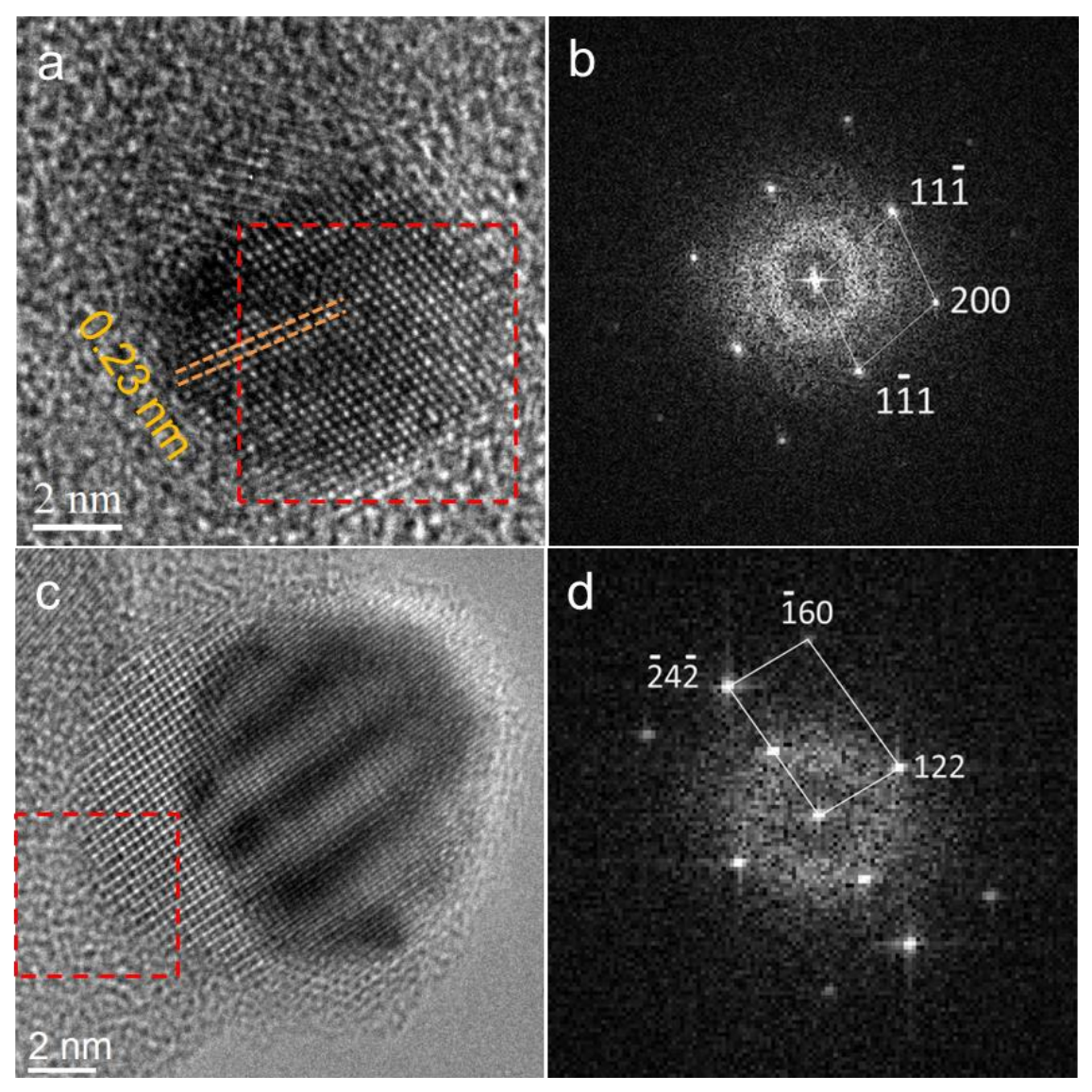

Figure 1. (a) A high resolution TEM image of an acorn-like Pt- $\mathrm{Fe}_{2} \mathrm{O}_{3}$ hybrid nanoparticle and (b) the FFT pattern of the dark part of the hybrid structure. (c) A high resolution TEM image of another Pt$\mathrm{Fe}_{2} \mathrm{O}_{3}$ hybrid nanoparticle and (d) the FFT pattern of the square part of the particle.

In addition, moiré pattern is observed in Figure 1c, suggesting that at least part of Pt is covered by $\mathrm{Fe}_{2} \mathrm{O}_{3}$ layer. Such an assignment is further confirmed by EELS on the hybrid nanoparticles. As shown in Supporting Information Figure S1b, the EELS spectrum from the cupule part exhibits the $\mathrm{L}_{3}$ and $\mathrm{L}_{2}$ 
peaks of $\mathrm{Fe}$ at $710 \mathrm{eV}$ and $722 \mathrm{eV}$, respectively, in agreement with the $\mathrm{L}_{3}$ and $\mathrm{L}_{2}$ edges of $\mathrm{Fe}$ in $\mathrm{Fe}_{2} \mathrm{O}_{3}$. In contrast, Fe signals on the dark embryo of the particle became negligible. The above characterization results suggest that the catalyst is a two-phase hybrid of $\mathrm{Fe}_{2} \mathrm{O}_{3}$ and Pt. The driving force for the hybrid $\mathrm{Pt}-\mathrm{Fe}_{2} \mathrm{O}_{3}$ catalyst formation could be the high temperature calcination. As $\mathrm{Pt}$ is a noble metal, therefore metallic $\mathrm{Pt}$ is the most stable phase.[14] In the case of $\mathrm{Fe}$, it tends to be oxidized to $\mathrm{Fe}_{2} \mathrm{O}_{3}$ which mainly has four crystalline polymorphs: $\alpha-\mathrm{Fe}_{2} \mathrm{O}_{3}, \beta-\mathrm{Fe}_{2} \mathrm{O}_{3}, \gamma-\mathrm{Fe}_{2} \mathrm{O}_{3}$ and $\varepsilon-\mathrm{Fe}_{2} \mathrm{O}_{3}$.[15] Although the observed orthorhombic $\mathrm{Fe}_{2} \mathrm{O}_{3}\left(\varepsilon-\mathrm{Fe}_{2} \mathrm{O}_{3}\right)$ is thermodynamically metastable, it can exist in the form of nanostructures. $[15,16]$
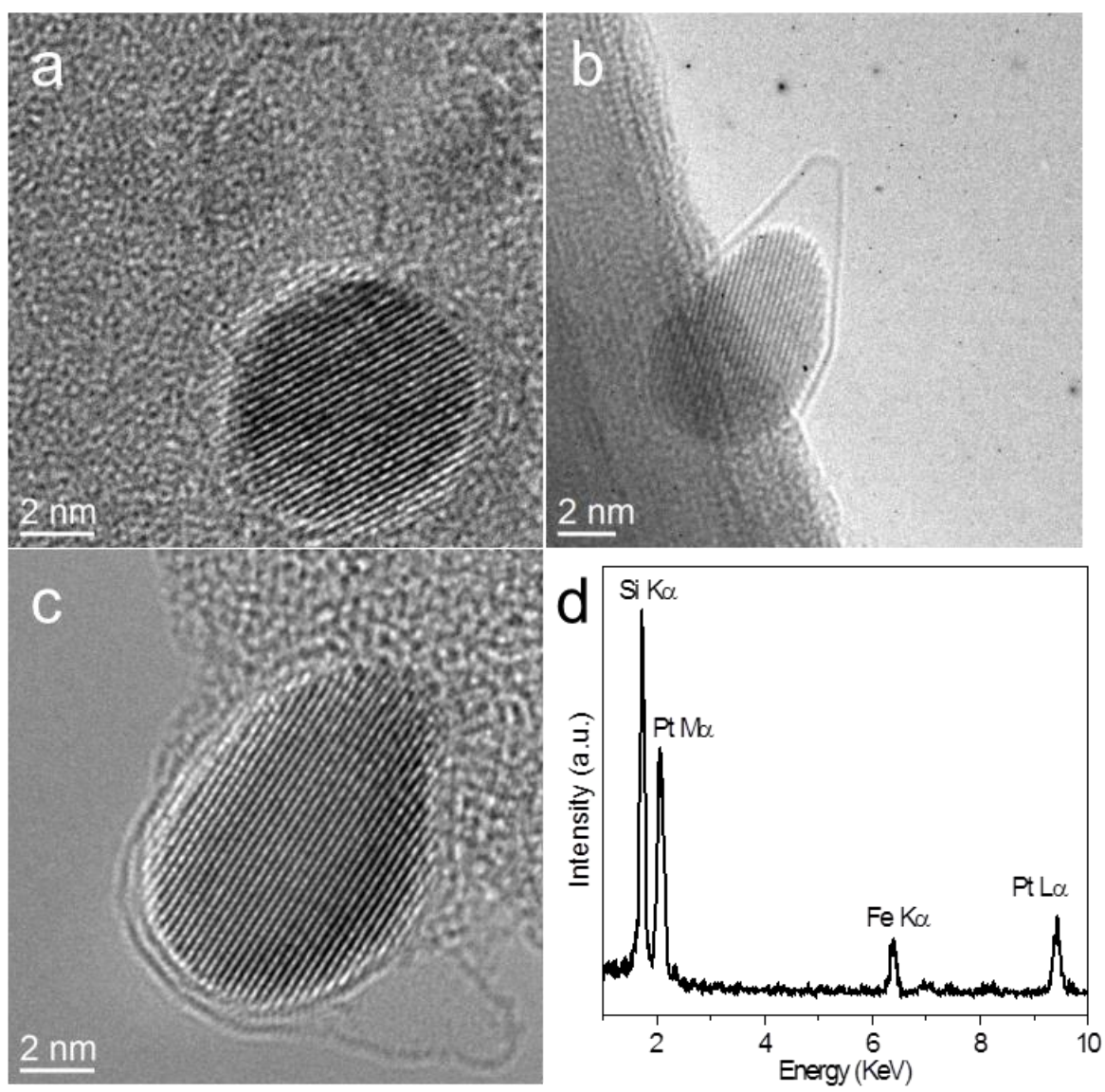

Figure 2. (a)(b)(c) TEM images of active PtFe nanoparticles after CVD process. (d) A typical EDX spectrum of an individual nanoparticle after CVD, showing the presence of both Fe and Pt. 
Carbon nanotubes were grown on the $\mathrm{Pt}-\mathrm{Fe}_{2} \mathrm{O}_{3}$ catalyst using $\mathrm{CO}$ as the carbon precursor at different temperatures. A TEM overview of SWCNTs produced after CVD reaction at $800{ }^{\circ} \mathrm{C}$ is presented in ESI Figure S2. Figure 2a-2c present TEM images typifying three nanoparticles which nucleate short carbon nanotubes after $\mathrm{CVD}$ reaction at $800{ }^{\circ} \mathrm{C}$. In contrast to the two-phase hybrid before reaction, all the particles display a single phase only. Further considering the presence of both $\mathrm{Pt}$ and $\mathrm{Fe}$ in the catalyst, as evidenced by the EDX spectrum (Figure 2d), it is concluded that PtFe alloy forms during CVD. Systematic EDX characterizations were performed on a number of PtFe particles after CVD. ESI Figure S3a depicts the histogram of Pt atomic percentages, which shows that most particles have near-equal atomic percentages of Pt and Fe. From their binary phase diagram (ESI Figure S3b), it can be seen that in a wide composition range (Pt atomic percentage of 32\% 60\%) these particles tend to adopt a chemically disordered FCC structure, where Pt atoms are randomly substituted by Fe atoms in the lattice. The FCC structure of PtFe nanoparticles is also confirmed by their FFT patterns (ESI Figure S4). Overall, after CVD reaction, most hybrid $\mathrm{Pt}-\mathrm{Fe}_{2} \mathrm{O}_{3}$ nanoparticles transformed into FCC PtFe alloy nanoparticles.

\subsection{Investigations of dynamics of Pt- $\mathrm{Fe}_{2} \mathrm{O}_{3}$ catalyst and nucleation of carbon nanotube by environmental} TEM

As indicated by TEM investigations of WCo catalysts, $[6,7]$ it is complicated to assign the active components for SWCNT growth, the structure and the composition of which could change with prolonged reaction time. In $\mathrm{CO}$ hydrogenation, the addition of Pt substantially improves the reducibility of $\mathrm{Fe}_{2} \mathrm{O}_{3},[17]$ which can be ascribed to the spillover effect of reductive species on Pt. Similarly, the improved reducibility of $\mathrm{Fe}_{2} \mathrm{O}_{3}$ in the presence of $\mathrm{Pt}$ is of great importance for nucleation and growth of carbon nanotubes, as reduction of $\mathrm{Fe}_{2} \mathrm{O}_{3}$ is a prerequisite for catalytic dissociation of carbon source and dissolution of carbon atoms. In order to further study evolutions of $\mathrm{Pt}^{-} \mathrm{Fe}_{2} \mathrm{O}_{3}$ hybrid nanoparticles during 
CVD and identify the active components for carbon nanotube nucleation, in situ environmental TEM was performed.

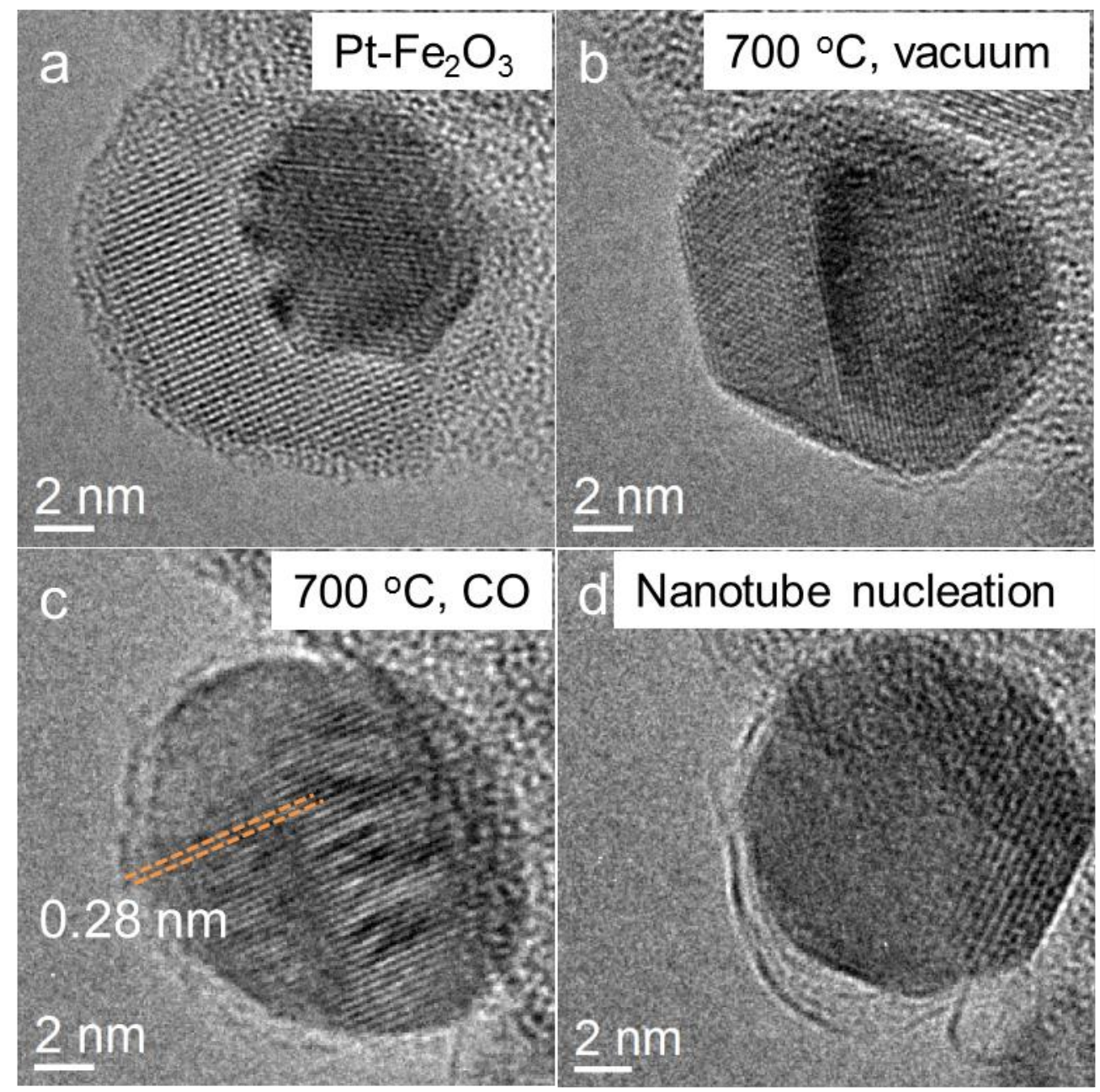

Figure 3. Evolutions of a Pt- $\mathrm{Fe}_{2} \mathrm{O}_{3}$ hybrid particle monitored by environmental TEM: (a) as-prepared particle; (b) Heated to $700{ }^{\circ} \mathrm{C}$ in vacuum; (c) Introduction of $\mathrm{CO}$ at $700{ }^{\circ} \mathrm{C}$; (d) Nucleation of a carbon nanotube.

Figure 3 shows a sequence of TEM images taken by following the same isolated $\mathrm{Pt}-\mathrm{Fe}_{2} \mathrm{O}_{3}$ particle. Figure 3a presents the acorn-like $\mathrm{Pt}-\mathrm{Fe}_{2} \mathrm{O}_{3}$ particle at room temperature which contains a dark Pt embryo and a light $\mathrm{Fe}_{2} \mathrm{O}_{3}$ cupule. Based on the FFT pattern of the $\mathrm{Fe}_{2} \mathrm{O}_{3}$ cupule (ESI Figure S5), the $\mathrm{Fe}_{2} \mathrm{O}_{3}$ can be well assigned as $\varepsilon-\mathrm{Fe}_{2} \mathrm{O}_{3}$, in agreement with the assignments of other $\mathrm{Fe}_{2} \mathrm{O}_{3}$ cupules shown in Figure 
1. With the increase of the temperature, the morphology of the $\mathrm{Pt}-\mathrm{Fe}_{2} \mathrm{O}_{3}$ changes, as indicated by Figure 3b. The morphology change could be related to the phase transformation from $\varepsilon-\mathrm{Fe}_{2} \mathrm{O}_{3}$ to $\beta-\mathrm{Fe}_{2} \mathrm{O}_{3}$, with a cubic structure and a lattice parameter of $0.939 \mathrm{~nm}$ (ESI Figure S6). With the introduction of CO, $\mathrm{Fe}_{2} \mathrm{O}_{3}$ is reduced to metallic $\mathrm{Fe}$ and the particle is thus transformed into a spherical-like shape (Figure 3c). In the middle of the catalyst, there is a boundary region. The left part of the particle is assigned as metallic Fe, with a plane spacing of $0.28 \mathrm{~nm}$, corresponding to that of the Fe (001) interplanar spacings (pdf card: 06-0696). While in the right of the boundary region, moiré fringes were observed, suggesting that the Pt is overlaid by the reduced Fe.

With prolonged exposure to $\mathrm{CO}$ at $700{ }^{\circ} \mathrm{C}$, carbon nanotube cap was observed to form from the left part of the particle (Figure 3d). Clearly, the left part of the particle differs greatly from its right part. The measured one-dimensional fringe-spacing $(0.38 \mathrm{~nm})$, visible for the right part, is consistent with (100) spacing of PtFe alloy structure (pdf card: 29-0718). Analyzing the FFT pattern of the left part (ESI Figure S7) gives an assignment of $\mathrm{Fe}_{2.5} \mathrm{C}$, the Hägg carbide. Such metastable Hägg carbide phase has been widely observed in Fischer-Tropsch process, especially at a high carbon chemical potential.[18] Besides $\mathrm{Fe}_{2.5} \mathrm{C}$, cementite $\left(\mathrm{Fe}_{3} \mathrm{C}\right)$ is another carbide that usually formed when exposing $\mathrm{Fe}$ catalyst to CO.[18, 19] In previously reported in situ environmental TEM experiments on monometallic $\mathrm{Fe}$ catalysts, $\mathrm{Fe}_{3} \mathrm{C}$ formation occurs more readily and catalyzes the subsequent carbon nanotube growth.[20-22] Different from monometallic Fe catalyst, in our PtFe catalyst, Fe tends to form Hägg carbide $\left(\mathrm{Fe}_{2.5} \mathrm{C}\right)$ phase in the presence of $\mathrm{CO}$, which could be related to the presence of Pt.[8, 17] As discussed by Wei et al., [18] $\mathrm{Fe}_{2.5} \mathrm{C}$ can be stabilized under high carbon chemical potential at temperatures resembling our reaction conditions. The Pt promotes the reduction and carburization of $\mathrm{Fe}_{2} \mathrm{O}_{3}$ by a spillover effect, facilitating the formation of carbon-rich $\mathrm{Fe}_{2.5} \mathrm{C}$. [8, 17] The finding is consistent with that of $\mathrm{Yu}$ et al.[17] who studied the effect of Pt on a Fe-based Fischer-Tropsch catalyst. However, it is noted that with long enough 
reaction time $(1 \mathrm{~h})$, the catalyst evolved into single-crystalline PtFe alloy phase (ESI Figure S8), in agreement with ex situ TEM investigations (Figure 2). Schematic illustration of carbon nanotube nucleation from the acorn-like $\mathrm{Pt}-\mathrm{Fe}_{2} \mathrm{O}_{3}$ catalyst is presented in Figure 4.

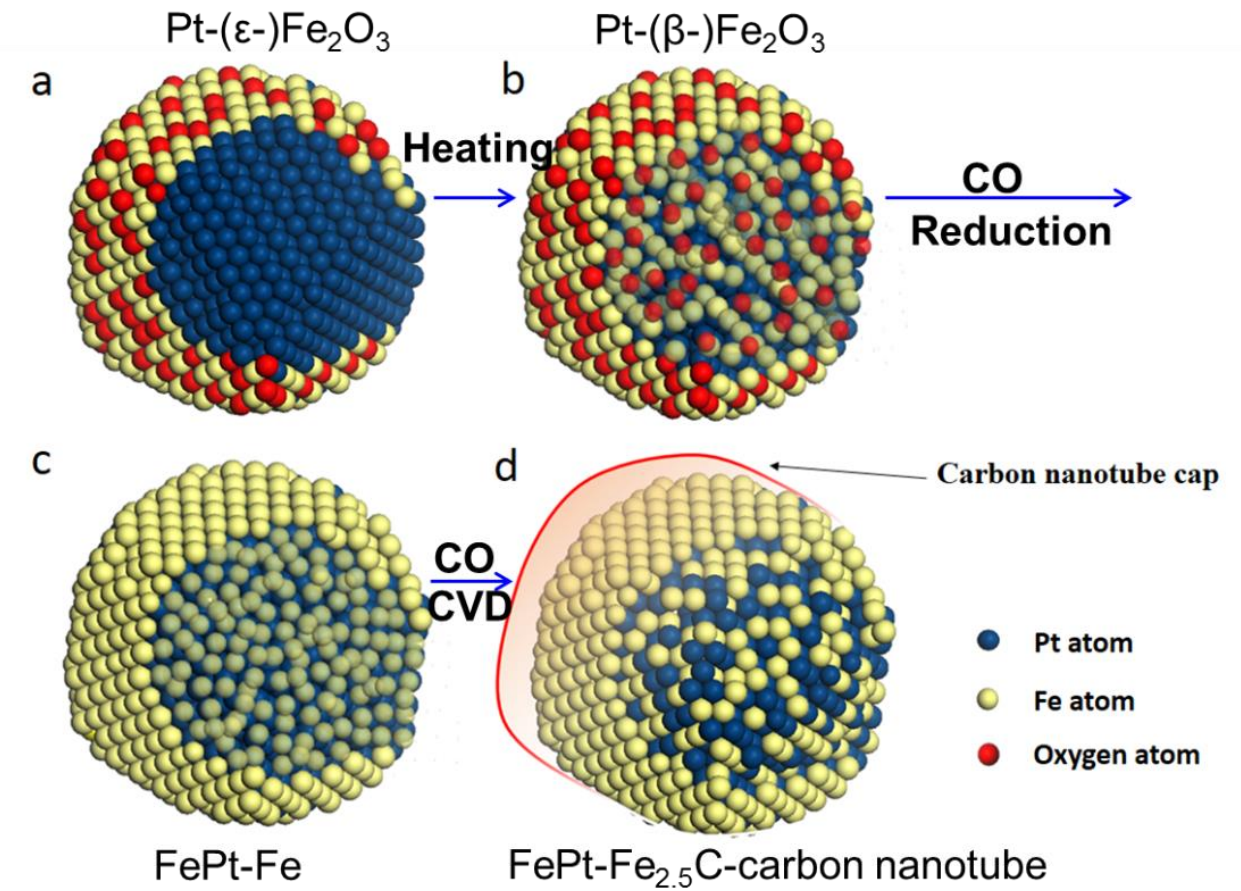

Figure 4. Schematic illustration of carbon nanotube nucleation from the $\mathrm{Pt}-\mathrm{Fe}_{2} \mathrm{O}_{3}$ hybrid catalyst.

\subsection{Characterizations of SWCNTs grown by CVD}

In general, the chirality of an SWCNT is determined by the tube cap, which is formed at the beginning of SWCNT nucleation.[23, 24] Therefore, under certain CVD conditions, the catalyst structure, which is related to the composition and carbon solubility of the nanoparticle, [24-27] could determine the chirality distribution of the SWCNT product. As revealed by in situ environmental TEM, in the reduced $\mathrm{PtFe}$ catalyst, it is the Hägg carbide instead of PtFe alloy that catalyzes the nucleation of carbon nanotubes. Therefore, in order to further clarify the SWCNT nucleation mechanisms, nanobeam electron diffraction was performed to study SWCNTs grown at different temperatures. 

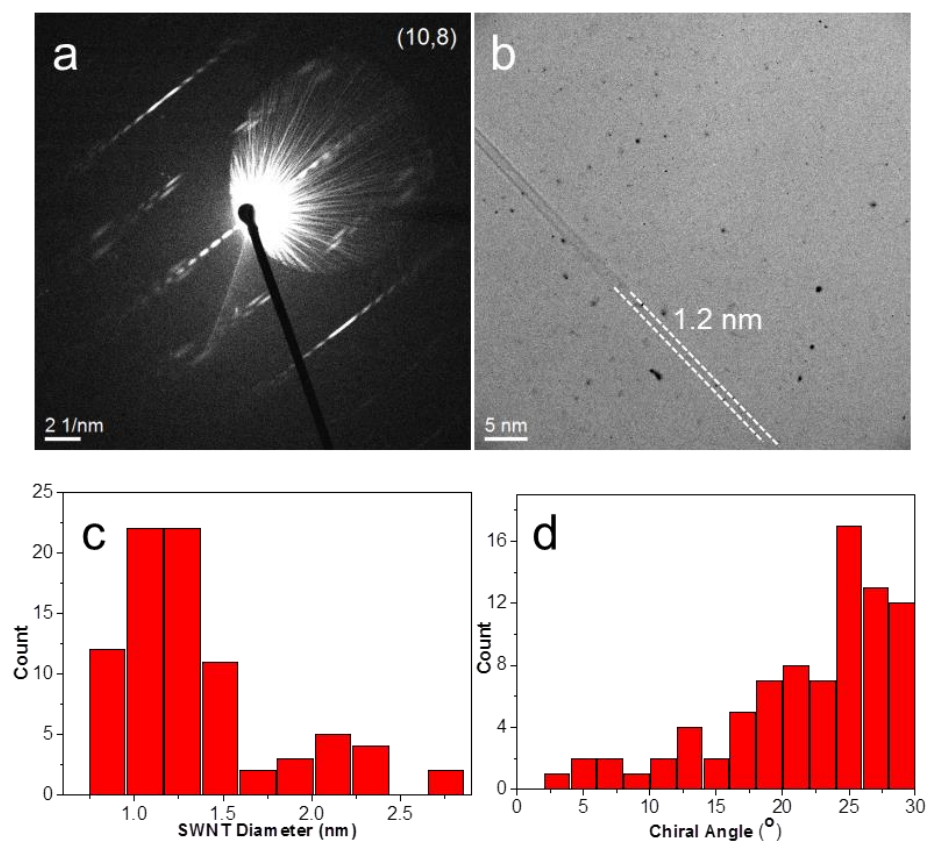

Figure 5. (a) A nanobeam electron diffraction pattern of the individual SWCNT shown in (b), the chirality of the SWCNT is identified as $(10,8)$. (c) Diameter distribution and (d) chirality distribution of SWCNTs grown on $\mathrm{Pt}-\mathrm{Fe}_{2} \mathrm{O}_{3}$ catalyst at $800^{\circ} \mathrm{C}$ using $\mathrm{CO}$ as the carbon source.

Figure 5a and $\mathbf{5 b}$ present a diffraction pattern of a suspended SWCNT grown at $800{ }^{\circ} \mathrm{C}$ and its TEM image. The sharp diffraction spots appear smeared because of radial curvature, forming a series of layer lines. The chiral angle and diameter of the SWCNT can be calculated respectively from the axial distances of the layer lines from the equatorial line and the pseudo-period of the equatorial oscillation.[28, 29] Accordingly, the tube with the diffraction pattern shown in Figure 5a is identified as having the chiral indices of $(10,8)$, a semiconducting tube with a diameter of $1.2 \mathrm{~nm}$, which is in agreement with the diameter determined from the real space measurement (Figure 5b). The histograms of tube diameter and chiral angle are shown in Figure $5 \mathbf{c}$ and $\mathbf{5 d}$. The mean diameter of SWCNTs grown at $800{ }^{\circ} \mathrm{C}$ is 1.35 $\mathrm{nm}$. The formation of small-diameter SWCNTs from large-size catalyst particle is attributed to selective nucleation on small-diameter particles and the perpendicular growth mode when using $\mathrm{CO}$ as the carbon source, $[25,30]$ as demonstrated in Figure 2. Similar to Fe-grown SWCNTs synthesized under similar 
growth conditions, $[31,32]$ the PtFe-grown SWCNTs are biased at large chiral angles, 57 out of $83(68 \%)$ have chiral angle larger than $20^{\circ}$. Meanwhile, the observed semiconducting SWCNTs have a fraction of $71 \%$, suggesting no selection to the conductivity of SWCNTs. The similar chirality distributions between PtFe-grown SWCNTs and Fe-grown SWCNTs further indicates that the active component for SWCNT nucleation could be similar. The chirality of an SWCNT is defined either by epitaxial relationship with the catalyst [24] or by specific growth mode. [30]

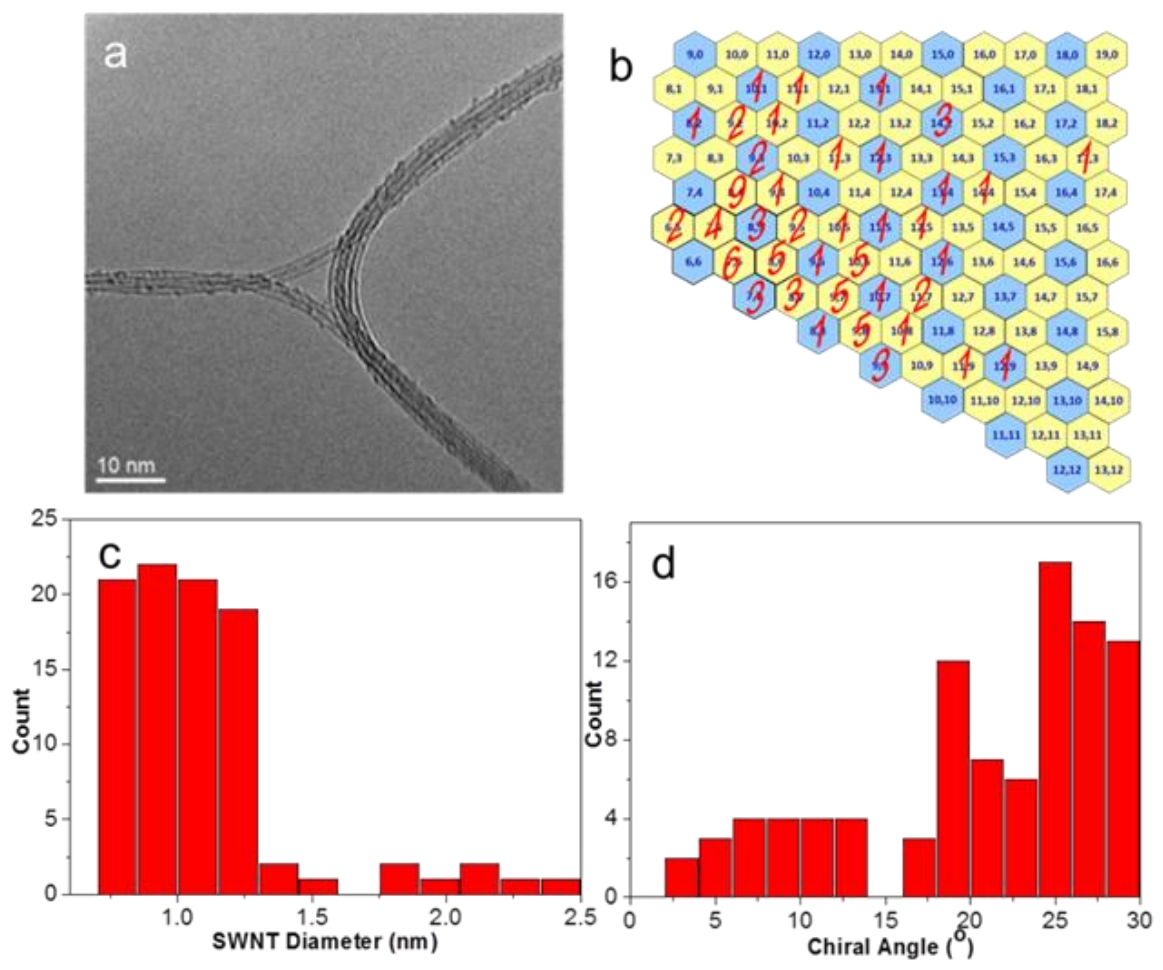

Figure 6. (a) A TEM overview of SWCNTs grown at $700^{\circ} \mathrm{C}$ by catalytic decomposition of $\mathrm{CO}$; (b) Chiral map of SWCNTs without 7 large diameter ones, namely, $(24,6),(17,15),(14,13),(28,6),(16,12)$, $(23,2)$ and $(21,11)$. (c) Diameter distribution and (d) chirality distribution of SWCNTs grown on Pt$\mathrm{Fe}_{2} \mathrm{O}_{3}$ catalyst at $700{ }^{\circ} \mathrm{C}$.

Nevertheless, different from monometallic Fe supported by $\mathrm{Si}_{4} \mathrm{~N}_{3}$ grid, which can only afford the growth of carbon nanotubes at temperatures over $\sim 800{ }^{\circ} \mathrm{C}$, the $\mathrm{Pt}-\mathrm{Fe}_{2} \mathrm{O}_{3}$ catalyst could grow SWCNTs at 
a lower temperature because of the spillover effect of Pt. [17] Figure 6a depicts a TEM image of carbon nanotubes, showing that single-walled nanotubes with small diameter were produced. The chirality map, the diameter distribution and chirality distribution of SWCNTs are presented in Figure $6 \mathbf{b}-6 \mathbf{d}$. The SWCNTs exhibit a small mean diameter of $1.09 \mathrm{~nm}$ and most of the tubes are in the diameter range from 0.7 to $1.2 \mathrm{~nm}$. Similar to $800{ }^{\circ} \mathrm{C}$-grown SWCNTs, the SWCNTs synthesized at $700{ }^{\circ} \mathrm{C}$ also show a preference to large chiral angles $\left(20^{\circ}-30^{\circ}\right)$. There is no high selectivity to certain $(\mathrm{n}, \mathrm{m})$ species, but $(8$, $4),(7,6),(8,6),(9,7),(9,8)$ and $(10,6)$ tubes occupy more than $37 \%$ of the total.

\section{Conclusions}

To summarize, we have described an acorn-like $\mathrm{Pt}_{-} \mathrm{Fe}_{2} \mathrm{O}_{3}$ hybrid catalyst for growing SWCNTs by catalytic decomposition of CO. In situ environmental TEM studies reveal that the presence of $\mathrm{Pt}$ promotes the carburization of reduced Fe, leading to the formation of Hägg carbide which catalyzes the nucleation of SWCNTs. Prolonged exposure of the hybrid catalyst to $\mathrm{CO}$ at reaction temperature leads to the formation of single-crystalline PtFe alloy, as also revealed by ex situ TEM characterizations. Meanwhile, the chirality distribution of SWCNTs grown at $800{ }^{\circ} \mathrm{C}$ is similar to that of SWCNTs grown on monometallic Fe nanoparticles, as the active components in both cases are quite similar. In addition, Pt facilitates the reduction of $\mathrm{Fe}_{2} \mathrm{O}_{3}$, accounting for SWCNT growth at a relatively low temperature of $700{ }^{\circ} \mathrm{C}$. This work not only helps understand the structure evolution of $\mathrm{Pt}^{-} \mathrm{Fe}_{2} \mathrm{O}_{3}$ bimetallic system and opens the way to a profound understanding of the heterogeneous catalysis, but also guides the design of bimetallic catalyst for the growth of SWCNTs.

\section{Acknowledgement}

The authors would like to acknowledge Scientific Research Foundation of Shandong University of Science and Technology for Recruited Talents (No. 2016RCJJ001), the Natural Science Foundation of 
China (No. 51272141) and Taishan Scholars Project of Shandong (No. TS20110828). The research leading to these results has received funding from the European Union Seventh Framework Programme (FP7/2007-2013) under grant agreement $\mathrm{n}^{\circ} 604472$ (IRENA project). The work made use of the Aalto University Nanomicroscopy Center (Aalto-NMC) premises.

Supplementary data: More characterization and analysis results of $\mathrm{Pt}-\mathrm{Fe}_{2} \mathrm{O}_{3}$ nanoparticles and carbon nanotubes grown on them by CVD.

\section{References}

[1] Iijima S and Ichihashi T, Single-shell carbon nanotubes of 1-nm diameter, Nature, 1993; 363: 6035.

[2] Bachilo S M, Balzano L, Herrera J E, Pompeo F, Resasco D E and Weisman R B, Narrow (n,m)distribution of single-walled carbon nanotubes grown using a solid supported catalyst, J Am Chem Soc, 2003; 125: 11186-7.

[3] He M, Chernov A I, Fedotov P V, Obraztsova E D, Sainio J, Rikkinen E, et al., Predominant $(6,5)$ single-walled carbon nanotube growth on a copper-promoted iron catalyst, J Am Chem Soc, 2010; 132: 13994-6.

[4] Li X, Tu X, Zaric S, Welsher K, Seo W S, Zhao W, et al., Selective synthesis combined with chemical separation of single-walled carbon nanotubes for chirality selection, J Am Chem Soc, 2007; 129: 157701.

[5] Liu B, Ren W, Li S, Liu C and Cheng H M, High temperature selective growth of single-walled carbon nanotubes with a narrow chirality distribution from a CoPt bimetallic catalyst, Chem Commun, 2012; 48: 2409-11. 
[6] Yang F, Wang X, Zhang D, Yang J, Luo D, Xu Z, et al., Chirality-specific growth of single-walled carbon nanotubes on solid alloy catalysts, Nature, 2014; 510: 522-4.

[7] An H, Kumamoto A, Takezaki H, Ohyama S, Qian Y, Inoue T, et al., Chirality specific and spatially uniform synthesis of single-walled carbon nanotubes from a sputtered $\mathrm{Co}-\mathrm{W}$ bimetallic catalyst, Nanoscale, 2016; 8:14523-9.

[8] Baker R T K and Waite R J, Formation of carbonaceous deposits from the platinum-iron catalyzed decomposition of acetylene, J Catal, 1975; 37: 101-5.

[9] Ohashi T and Shima T, Synthesis of vertically aligned single-walled carbon nanotubes with metallic chirality through facet control of catalysts, Carbon, 2015; 87: 453-61.

[10] Xin H L, Alayoglu S, Tao R, Genc A, Wang C M, Kovarik L, et al., Revealing the atomic restructuring of Pt-Co nanoparticles, Nano Lett, 2014; 14: 3203-7.

[11] Tao F F and Salmeron M, In situ studies of chemistry and structure of materials in reactive environments, Science, 2011; 331: 171-4.

[12] He M, Zhang L, Jiang H, Yang H, Fossard F, Cui H, et al., Fe-Ti-O based catalyst for large-chiralangle single-walled carbon nanotube growth, Carbon, 2016; 107: 865-71.

[13] He M, Duan X, Wang X, Zhang J, Liu Z and Robinson C, Iron catalysts reactivation for efficient CVD growth of SWNT with base-growth mode on surface, J Phys Chem B, 2004; 108: 12665-8.

[14] Liu C, Klemmer T J, Shukla N, Wu X, Weller D, Tanase M, et al., Oxidation of FePt nanoparticles, J Magn Magn Mater, 2003; 266: 96-101.

[15] Machala L, Tuček J i and Zboril R, Polymorphous transformations of nanometric iron (III) oxide: a review, Chem Mater, 2011; 23: 3255-72.

[16] Tuček J, Machala L, Ono S, Namai A, Yoshikiyo M, Imoto K, et al., Zeta-Fe2O3 - A new stable polymorph in iron(III) oxide family, Sci Rep, 2015; 5: 15091. 
[17] Yu W, Wu B, Xu J, Tao Z, Xiang H and Li Y, Effect of Pt Impregnation on a precipitated ironbased Fischer-Tropsch synthesis catalyst, Catal Lett, 2008; 125: 116-22.

[18] Wei Q, Pippel E, Woltersdorf J and Grabke H J, Microprocesses of coke formation in metal dusting, Mater Corr, 1999; 50: 628-33.

[19] Herranz T, Rojas S, Pérez-Alonso F J, Ojeda M, Terreros P and Fierro J L G, Genesis of iron carbides and their role in the synthesis of hydrocarbons from synthesis gas, J Catal, 2006; 8199: 40199-211.

[20] C. T. Wirth, B. C. Bayer, A. D. Gamalski, Esconjauregui S, Weatherup R S, Ducati C, et al., The phase of iron catalyst nanoparticles during carbon nanotube growth, Chem Mater, 2012; 24: 4633-40.

[21] Yoshida H, Takeda S, Uchiyama T, Kohno H and Homma Y, Atomic-scale in-situ observation of carbon nanotube growth from solid state iron carbide nanoparticles, Nano Lett, 2008; 8: 2082-6.

[22] Mazzucco S, Wang Y, Tanase M, Picher M, Li K, Wu Z, et al., Direct evidence of active and inactive phases of Fe catalyst nanoparticles for carbon nanotube formation, J Catal, 2014; 319: 54-60.

[23] Zhao Q, Xu Z, Hu Y, Ding F and Zhang J, Chemical vapor deposition synthesis of near-zigzag single-walled carbon nanotubes with stable tube-catalyst interface, Sci Adv, 2016; 2: e1501729.

[24] Chiang W-H and Mohan Sankaran R, Linking catalyst composition to chirality distributions of asgrown single-walled carbon nanotubes by tuning NixFe1-x nanoparticles, Nat Mater, 2009; 8: 882-6.

[25] He M, Fedotov P V, Chernov A, Obraztsova E D, Jiang H, Wei N, et al., Chiral-selective growth of single-walled carbon nanotubes on Fe-based catalysts using CO as carbon source, Carbon, 2016; 108: $521-8$.

[26] He M, Amara H, Jiang H, Hassinen J, Bichara C, Ras R H, et al., Key roles of carbon solubility in single-walled carbon nanotube nucleation and growth, Nanoscale, 2015; 7: 20284-9.

[27] Harutyunyan A R, Chen G, Paronyan T M, Pigos E M, Kuznetsov O A, Hewaparakrama K, et al., Preferential growth of single-walled carbon nanotubes with metallic conductivity, Science, 2009; 326: 116-20. 
[28] Jiang H, Nasibulin A, Brown D and Kauppinen E, Unambiguous atomic structural determination of single-walled carbon nanotubes by electron diffraction, Carbon, 2007; 45: 662-7.

[29] Meyer J C, Paillet M, Duesberg G S and Roth S, Electron diffraction analysis of individual singlewalled carbon nanotubes, Ultramicroscopy, 2006; 106: 176-90.

[30] Fiawoo M F C, Bonnot A M, Amara H, Bichara C, Thibault-Penisson J and Loiseau A, Evidence of correlation between catalyst particles and the single-wall carbon nanotube diameter: a first step towards chirality control, Phys Rev Lett, 2012; 108: 195503.

[31] He M, Jiang H, Kauppinen E I and Lehtonen J, Diameter and chiral angle distribution dependencies on the carbon precursors in surface-grown single-walled carbon nanotubes, Nanoscale, 2012; 4: 7394-8. [32] Mustonen K, Laiho P, Kaskela A, Zhu Z, Reynaud O, Houbenov N, et al., Gas phase synthesis of non-bundled, small diameter single-walled carbon nanotubes with near-armchair chiralities, Appl Phys Lett, 2015; 107: 013106. 